\title{
doispontos:
}

\section{Abelardo e a teoria contemporânea da virtude (virtue theory)}

\author{
Abelard and the Contemporary Virtue Theory
}

\author{
Guy Hamelin \\ Universidade de Brasília - UnB \\ hamelingr@hotmail.com
}

\begin{abstract}
Resumo: A 'teoria da virtude' contemporânea enfatiza a necessidade de voltar à formação moral do indivíduo, seguindo o modelo ético disponibilizado por Aristóteles. Segundo Maclntyre, representante importante dessa teoria, o estoicismo favoreceu o desenvolvimento da ética moderna e contemporânea ao destacar noções como vontade, assentimento e lei natural ou divina. Por conseguinte, o desenvolvimento do próprio agente moral foi negligenciado. No século XII, Abelardo apresenta uma ética híbrida, que mantém, ao mesmo tempo, a teoria aristotélica da virtude e elementos da moral estoica. No presente estudo, consideramos a crítica feita por Maclntyre da ética abelardiana, estimada estar na origem das concepções morais modernas e contemporâneas.
\end{abstract}

Palavras-chave: Abelardo, Alasdair Maclntyre, Aristóteles, estoicismo, teoria da virtude, consentimento.

\begin{abstract}
The contemporary 'virtue theory' stresses the need to return to the moral formation of the individual, following the ethical model made available by Aristotle. According to Maclntyre, an important representative of this theory, Stoicism favored the development of modern and contemporary ethics, by highlighting notions such as will, consent, and natural or divine law. As a result, the development of the moral agent itself has been neglected. In the twelfth century, Abelard introduces hybrid ethics, which maintains both the Aristotelian theory of virtue and elements of Stoic morality. In the present study, we consider Maclntyre's criticism of Abelard ethics, which is estimated to be at the origin of modern and contemporary moral conceptions.
\end{abstract}

Keywords: Abelard, Alasdair MacIntyre, Aristotle, stoicism, virtue theory, consent. 


\section{Introdução}

A ética aristotélica ganhou novo alento, a partir da segunda metade do século XX, com a dita 'Teoria da virtude'. Seus defensores apresentam uma crítica severa a respeito das concepções éticas modernas e contemporâneas predominantes nos últimos cinco séculos. O retorno a Aristóteles permite, entre outras coisas, enfatizar a importância da formação moral do indivíduo, que tem desejos, interesses e necessidades, e não apenas deveres e obrigações.

Segundo MacIntyre, um dos mais importantes representantes dessa teoria contemporânea da virtude, o filósofo Pedro Abelardo tem certo papel precursor no desenvolvimento da ética moderna, ao destacar noções como vontade, intenção e consentimento, especialmente na sua explicação da falta moral. Deste modo, o autor da Idade Média negligenciaria, até certo ponto, a tradicional teoria aristotélica da virtude e, consequentemente, o caráter ( $\tilde{\eta} \theta$ o $)$ do indivíduo no agir moral. De acordo com MacIntyre, a fonte à qual se referem Abelardo e seu célebre inspirador, Agostinho, é o estoicismo, que não somente liga o essencial da vida moral interna a uma Lei natural ou divina externa, mas também diminui a relevância da virtude, colocando-a num patamar inatingível.

Em nossa atual apresentação, queremos investigar a justeza dessas informações fornecidas por MacIntyre acerca da ética de Abelardo. Em outras palavras, o nosso propósito é mostrar até que ponto Abelardo constitui ao mesmo tempo um precursor da ética moderna e um renunciador parcial da teoria da virtude aristotélica. Para alcançar esse objetivo, examinamos, primeiro, a própria concepção da falta moral de Abelardo. Veremos, deste modo, a importância dada por nosso autor medieval às noções de vontade e de consentimento, além de ressaltar as principais fontes que o influenciaram acerca desses temas. $\mathrm{Na}$ continuação, consideramos em que consiste, basicamente, essa teoria contemporânea da virtude e quais são os seus principais representantes. Esse exame nos leva, em seguida, à própria análise de MacIntyre sobre a contribuição de Abelardo à história da ética e, propriamente, o seu aporte ou não na teoria da virtude. Apesar de apresentar um estudo bastante sério e pertinente da situação da moral abelardiana, MacIntyre oculta ou negligencia alguns elementos determinantes dessa ética para ele poder chegar, a nosso ver, a uma conclusão definitiva. Enfim, indicamos o que nos parece ser a principal contribuição da ética de Abelardo, que se revela ainda mais atual do que estima MacIntyre.

\section{I. Falta moral e consentimento em Abelardo}

O papa Urbano II escreve, no final do século XI, o seguinte: "Muitos atos parecem maus sem o serem na realidade, porque eles não procedem de uma má intenção." (Jolivet, 1994, p. 99) ${ }^{1}$.É nesse contexto histórico que Abelardo tenta dar, em sua Ética ou Conhece-te a ti mesmo (Ethica sive Scito teipsum) (Abaelardus, 1971, 2001) - chamada, daqui em diante, Ética -, uma explicação adequada à verdadeira causa da falta moral (peccatum). Em outras palavras, o que o penitente deve confessar? A ação má? O desejo mau? A vontade má? $\mathrm{Ou}$, talvez, a sua própria natureza viciosa? Urbano já avisa que não se devem avaliar somente os atos que podem, à primeira vista, parecer-nos condenáveis. A pena resultante da falta de moralidade tem de ser proporcional à maldade cometida. Ela não pode ser unicamente dependente dos atos visíveis ou dos repertórios, famosos na época, que enumeram listas de pecados e penas correspondentes a serem cumpridas, como os Instituta canonum ou os Instituta sanctorum patrum (Abaelardus, 1971, pp. xxxii-xxxiii, 104-105, 108-109; Cross \& Levingstone, 1974, pp. 1059-1060). Na presente parte, examinamos a resposta dada por Abelardo na Ética à seguinte pergunta: o que deve ser condenado? Essa investigação nos permite distinguir, em um primeiro momento, as principais noções ligadas à questão da falta moral. Em seguida, tentamos identificar as fontes às quais se refere Abelardo nessa questão.

\footnotetext{
${ }^{1}$ Traduzimos. "Beaucoup d'actes paraissent mauvais sans l'être en réalité, parce qu'ils ne procèdent pas d'une intention mauvaise (...)."
} 
No tratado Ética, Abelardo afirma nitidamente que a falta moral não resulta da má ação, nem da vontade prava ou do desejo perverso, nem sequer do vício, mas, sim, do ato interior de consentimento. Vejamos o que diz sobre isso:

\begin{abstract}
"Por isso, o vício é aquilo pelo qual estamos em um estado predisposto a pecar, ou seja, estamos inclinados a consentir (ad consenciendum) no que não é conveniente, de tal forma que o fazemos ou o evitamos. Agora, esse consentimento (consensum), chamamo-lo propriamente de pecado, isto é, a culpa da alma, pela qual ela merece a danação ou se torna culpável diante de Deus. Pois o que é esse consentimento, se não for o desprezo (contemptus) a Deus e uma ofensa a Ele?" (Abaelardus, 2001, p. 3)2.
\end{abstract}

Nesse trecho, Abelardo enfatiza em que consiste a falta moral. Não se trata do vício, mesmo que nos predisponha eventualmente a cometê-la. Sendo o principal aguilhão para incitar o mau agir, o caráter vicioso de um indivíduo constitui um elemento de importância fundamental para qualquer ética antiga, notadamente aristotélica, mas o vício não constitui por si só a falta moral para Abelardo. O que nos torna culpável é consentir em ofender a Vontade divina. Essa conduta para com Deus exclui, de imediato, tanto a ação externa que segue o consentimento, quanto o desejo ruim ou a má vontade que o precede da esfera pecaminosa. Segundo Abelardo, o ato exterior não aumenta, de maneira alguma, a falta, nem a vontade, como diz nesta passagem:

"Portanto, qualquer realização das ações (operum exsecucio) é irrelevante no aumento do pecado e nada macula a alma a não ser o que é dela, a saber, o consentimento (consensus), que somente é, como dissemos, o pecado, e não a vontade que o precede, nem a execução da ação que o segue." (Abaelardus, 2001, p. 15) 3 .

As palavras de Abelardo são claras no que diz respeito à natureza da falta moral. É preciso, todavia, esclarecer o que entende, neste contexto, por vontade, já que a realidade à qual se refere esse termo é suscetível de levar à confusão. Abelardo parece considerar que o vocábulo voluntas é impreciso demais para que seja usado na identificação da falta moral. Na sua obra, tanto ética, como teológica, voluntas concerne, em geral, ao desejo ou à concupiscência que precede, como vimos, o consentimento ${ }^{4}$. Há algumas exceções a esse uso, como pode ser visto no tratado intitulado Commentaria in Epistolam Pavli ad Romanos, no qual o autor afirma: “(...) propriamente dito, < o pecado diz respeito> à culpa mesma da alma e ao desprezo de Deus, isto é, à nossa vontade prava, pela qual nos erguemos culpáveis diante de Deus (...).” (Abaelardus, 1969, p. 164) . Nesse último caso preciso, Abelardo diz que retoma o que é dito sobre o pecado nas Escritura. Seja como for, Abelardo tenta, na Ética, precisar o seu vocabulário, empregando, na maioria das vezes, voluntas no sentido mais restrito de desejo, que certamente não corresponde à boulêsis

\footnotetext{
${ }^{2}$ Traduzimos. "Vicium itaque est, quo ad peccandum proni efficimur, hoc est inclinamur ad consenciendum ei, quod non conuenit, ut illud scilicet faciamus aut dimittamus. Hunc uero consensum proprie peccatum nominamus, hoc est culpam anime, qua dampnacionem meretur, uel apud deum rea statuitur. Quid est enim hic consensus nisi dei contemptus et offensa illius?"

${ }^{3}$ Traduzimos. "Nichil igitur ad augmentum peccati pertinet qualiscumque operum exsecucio, et nichil animam, nisi quod ipsius est, inquinat, hoc est consensus, quem solummodo esse peccatum diximus, non uoluntatem eum precedentem uel actionem operis subsequentem."

${ }^{4}$ Abelardo parece concordar com a tese que deixa entender que o pecado não pode ser uma substância, que seria criada por Deus, ou seja, ele não pode ser algo positivo, como afirmava Agostinho. Mas nosso autor é contrário, salvo raras exceções, à ideia segundo a qual ele seria, antes, uma má vontade, como era defendido, na época de Abelardo, pelos representantes da Escola de Anselmo de Laon. Cf. (Blomme, 1958, pp. 10-12; Abaelardus, 1971, p. 8, nota 2)

${ }^{5}$ Traduzimos. Essa frase foi extraída de uma passagem na qual Abelardo indica que existem, nas Escrituras, várias maneiras de chamar o pecado: "Pluribus autem modis peccati nomen Scriptura sacra accipit: uno quidem modo et proprie pro ipsa animi culpa et contemptu Dei, id est praua uoluntate nostra qua rei apud Deum statuimur (...).” Ver (Abaelardus, Expositio in epistolam Pauli ad Romanos, 1855, pp. 866B, 942B; 1971, p. 25, nota 5; 2001*, p. 74; 2001, p. 16).
} 


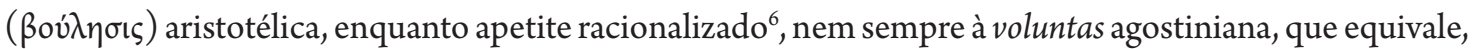
em certos contextos, ao consentimento abelardiano ${ }^{7}$. Em suma, Abelardo não estima, em geral, que a falta moral consista na má vontade, reduzida assim a um simples desejo natural, mesmo que concorde com os preceitos de Urbano II, segundo os quais a intenção, mais do que o ato, deve ser priorizada na avaliação do desvio no que se refere à vontade divina. Apesar disso, Abelardo foi condenado, no Concílio de Sens em 1040, por ter ensinado, o que refuta: "Quod neque opus neque voluntas (...) peccatum sit." (Abaelardus, Confessio fidei, 1855, pp. 107-108) ${ }^{8}$.

\section{II. As fontes da ideia abelardiana de consentimento (consensus)}

Identificar a natureza da falta moral ao consentimento não é uma novidade na história do pensamento, ainda que, na afirmação dessa concepção, Abelardo seja mais explícito e consistente que os seus predecessores. Agostinho é conhecido por ter defendido a tese de que a vontade é o princípio a partir do qual agimos. Sendo assim, a falta moral provém de uma má vontade e não de uma natureza fraca que deseja algo ruim e se deleita com esse algo. Essa concupiscência torna-se pecado somente quando a vontade aprova (approbare) tal impulso. Nesse caso, Agostinho usa, às vezes, consensus ou o equivalente, como no De continentia, no qual afirma: "(...) < o salmista> diz logo depois9" "Não deixes meu coração inclinar-se a palavras más." ${ }^{\prime 1}$. Essa inclinação do coração é algo diferente do próprio consentimento (consensus) ? (...) Mas se <alguém> consente, <então> já disse no seu coração, mesmo que não dissesse nada pela boca." (Augustinus, 1845, p. 350) ${ }^{11}$. No tratado Expositio ad Romanos, Agostinho é ainda mais explícito: "De fato, não pecamos por causa do próprio desejo (desiderio) mau, mas, sim, em razão do nosso consentimento." (Augustinus, 1841, p. 2066) ${ }^{12}$.

Agostinho é o inventor dessa concepção consensual da falta moral? Ainda que seja o propagador por excelência no Ocidente latino da ideia de vontade como fonte do agir e, em particular, da tese da falta moral como consentimento na má vontade, Agostinho retoma, nesse caso, a velha teoria psico-epistemológica do estoicismo antigo (Rohmer, 1954, pp. 491-498; Voelke, 1973, pp. 192, 199-200; O’Daly, 1987, pp. 89, 102). Sem entrar em detalhe, a noção estoica de assentimento ( $\sigma v \gamma \kappa \alpha \tau \dot{\theta} \theta \varepsilon \sigma \iota \varsigma)$, traduzida em latim por adsensio ou adsensus - ambos os termos equivalentes a consensus -, está estritamente ligada ao tema do critério de verdade ${ }^{13}$, que constitui o elemento-chave, servindo a justificar o caráter empírico do conhecimento.

${ }^{6}$ Cf. Aristoteles. De anima II, 3, 414a 29-34; III, 10, 433a 23-25. Nessa última referência, Aristóteles afirma claramente: “(...)

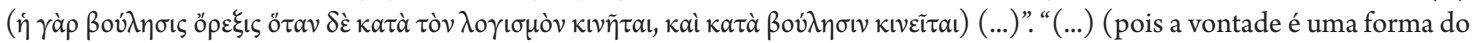
apetite; quando se move de acordo com o raciocínio, também se move de acordo com a vontade) (...)” Traduzimos. (Aristoteles, 1995, p. 188). Cf. Aristoteles. Ethica Nichomachea III, 4, 1111b 19-30; III, 6, 1113a 13-1113b 2; IX, 6, 1167 b 5-16.

${ }^{7}$ Há muitos textos de Agostinho nos quais encontramos essa ideia. Citamos apenas alguns deles: Augustinus. De duabus animabus contra Manichaeos X, XI, XII; De continentia II, 3; Sermo CLV, 1; Enarrationes in Psalmos CXVIII, 3; De libero arbitrio III, X, 29. Ver (Blomme, 1958, pp. 103-217; Lottin, 1942, pp. 21-32, 117-118; Hamelin, 1996, pp. 192-205; Abaelardus, 1971, p. xxxiv).

8 “O pecado não é nem o ato nem a vontade." Traduzimos. Ver (Abaelardus, 1971, pp. 8-9, nota 2; Blomme, 1958, pp. 261-274).

${ }^{9}$ Depois do trecho seguinte: “(2) Livra-me, Senhor, do homem malvado, protege-me do homem violento, (3) dos que planejam maldades no coração e, todo dia, suscitam conflitos! (4) Eles aguçam as línguas como a da serpente; há veneno de víbora em seus lábios." (Garmus, Salmos 140, 2-4, 1986, pp. 749-750)

${ }^{10}$ Salmo 141, 4. Numa versão contemporânea, encontramos: “Não deixes meu coração inclinar-se ao mal.” (Garmus, 1986, p. 750).

${ }^{11}$ Traduzimos. “(...) continuo subdidit: "Ne declines cor meum in verba maligna.” (PS CXLI, 4) Declinatio cordis quid est nisi consensio? (...) Si autem consensit, iam corde dixit, etiamsi ore non sonuit.”

12 Traduzimos. "Non enim in ipso desiderio pravo, sed in nostra consensione peccamus." Cf. Augustinus. Sermo III, VI; De sermone in monte I, 12, 34; Enarratio in Psalmum 3, 118.

${ }^{13}$ Damos nosso assentimento em impressões seguras, que respeitam critérios precisos; elas devem ser causadas por objetos reais com clareza e exatidão, etc. Ver: Long \& Sedley, 1987, pp. 241-253; Hamelin, 2010, pp. 180-183. 


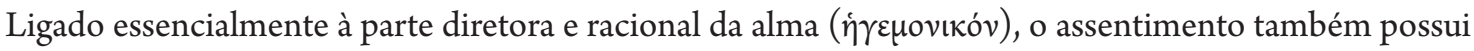
um papel decisivo no que diz respeito à conduta humana.

O assentimento estoico tem uma função intermediária determinante entre a impressão ( $\varphi \alpha v \tau \alpha \sigma i ́ \alpha)$ e o impulso (o $\rho \eta \eta ́)$, que lhe permite passar naturalmente da esfera do conhecimento ao âmbito da moral (Long \& Sedley, 1987, pp. 450-451). Em outras palavras, esse elo estrito que existe entre assentimento e impulso permite-nos confiar tanto na verdade, quanto no desejo em relação ao estado de coisas, que constitui o conteúdo de uma impressão, pois temos a capacidade de aceitar agir ou não agir. (Long \& Sedley, 1987, pp. 236-237).

\section{A Ética contemporânea da virtude}

Na segunda metade do século XX, surgiu um novo interesse pela teoria da virtude antiga e medieval, notadamente a de Aristóteles e a de Tomás de Aquino ${ }^{14}$. Inspirada e iniciada por pensadores como Elizabeth Anscombe (1957, 1958), Alasdair MacIntyre (1984), Philippa Foot (1967, 1978) e outros (Horton \& Mendus, 1994) ${ }^{15}$, essa corrente ressalta basicamente o seguinte ponto: a questão levantada a partir da ética moderna, "O que devo fazer?", talvez não seja adequada. Segundo alguns dos autores mencionados: “(...) parece impossível decifrar o significado enigmático de "dever moral” (Ph. Foot) (...)." (Silva Santos, 2001, p. 338) Deveríamos perguntar, antes: "Qual tipo de pessoa eu deveria ser?” (Pence, 1991, p. 249) Em outras palavras, como diz Marcia Baron em um artigo de referência nesse assunto: "Eu uso <a expressão $>$ "Ética da virtude" para $<$ me $>$ referir a todas as perspectivas que rejeitam que ser governado por um conceito de dever (isto é, do que deveríamos moralmente fazer (...)) é uma condição necessária para a pessoa perfeitamente moral." $(1985, \mathrm{p} .47)^{16}$.

Em um primeiro momento, a "teoria da virtude' contemporânea apresentou-se como uma crítica severa das concepções éticas preponderantes na sua época, como as das tradições iluminista e kantiana, do utilitarismo e do emotivismo, que deixam de lado o tema da virtude e do caráter ( $\tilde{\eta} \theta$ o $)$ do agente moral, que também possui interesses e desejos. A abordagem dessas teorias éticas reduz-se, como diz Bento Silva Santos, a um tema específico: “(...) a questão ética como problema da determinação da ação justa ou correta e das suas regras, e como problema da justificação do dever ou da obrigação de realizar ações justas e de seguir determinadas regras." (2001, p. 328).

Em um segundo momento, essa "teoria da virtude" quer resgatar a concepção ética dos pré-modernos, enfatizando sobretudo o fato de que é preciso voltar ao contexto histórico ${ }^{17}$, no qual foi desenvolvida essa ética, para entender o sentido exato das noções aperfeiçoadas na época, como as de virtude, caráter,

\footnotetext{
14 "A ética aristotélica é, para A. MacIntyre, a expressão paradigmática da moral da virtude, da qual esboça as vicissitudes históricas nas sociedades heroicas, em Atenas dos séculos V-VI a.C. até a Idade Média para verificar, em seguida, a que metamorfose radical é submetido o conceito de virtude na ética moderna." (Silva Santos, 2001, p. 336).

${ }^{15}$ Encontra-se uma boa síntese da questão em português em: (Silva Santos, 2001).

${ }^{16}$ Traduzimos. "I use "ethics of virtue" to refer to all those views which deny that it is a necessary condition of perfectly moral personhood that one be governed by a concept of duty (i.e., of what we morally ought to do (...))."

${ }^{17}$ Numa comparação com a incongruência da linguagem da ciência natural em um mundo ficcional descrito por MacIntyre, a linguagem da moral contemporânea também parece desconectada da realidade antiga à qual se refere: "The hypothesis which I wish to advance is that in the actual world which we inhabit the language of morality is in the same state of grave disorder as the language of natural science in the imaginary world which I described. (...) For a prerequisite for understanding the present disordered state of the imaginary world was to understand its history (...)" (MacIntyre, 1984, pp. 2-3).
} 
intenção e finalidade, entre outras ${ }^{18}$. Como afirma Greg Pence sobre isso: "Alasdair MacIntyre concordou com Anscombe e levou a análise dela mais adiante. Na visão dele, as sociedades modernas não herdaram uma única tradição ética do passado, mas sim fragmentos de tradições conflitantes: somos perfeccionistas platônicos, saudando os medalhistas de ouro nas olimpíadas; utilitaristas, aplicando o princípio de triagem ao ferido na guerra; lockianos, afirmando os direitos <legais> de propriedade; cristãos, idealizando a caridade, a compaixão e os valores morais iguais; e seguidores de Kant e Mill, afirmando a autonomia pessoal. Não é de se estranhar que as intuições estejam em desacordo na filosofia moral. Não é de se estranhar que as pessoas estejam confusas." (1991, p. 251) ${ }^{19}$. Em suma, a ética aristotélica seria, notadamente para MacIntyre, uma alternativa essencial à ética moderna.

A teoria da virtude contemporânea é, hoje em dia, uma concepção ética bem estabelecida, que continua a se fortalecer, aproveitando notadamente as críticas valiosas feitas por representantes das éticas moderna e contemporânea, que foram objeto de ataques (Silva Santos, 2001, pp. 347-357). Seja como for, a ética abelardiana encontra-se analisada na grande síntese histórica do livro Depois da virtude, de Alasdair MacIntyre, na seção consagrada à Idade Média intitulada "Aspectos medievais e ocasiões" (1984, pp. 165$180)^{20}$. Na verdade, o capítulo é bem eclético e diz respeito tanto a elementos da filosofia de Aristóteles, dos estoicos e d'outros pensadores, quanto a de autores medievais. Mesmo assim, aspectos importantes da ética abelardiana são examinados em detalhes. Na continuação imediata, queremos apresentar o que diz exatamente MacIntyre sobre o lugar ocupado por Abelardo na história da teoria da virtude.

\section{Crítica de MacIntyre da ética abelardiana}

É preciso indicar, de início, que o mundo medieval encontrou relativamente tarde a obra inteira de Aristóteles, o que deixa entender que autores da Idade Média anteriores à segunda metade do século XII, os quais possuíam somente parte limitada dessa produção, dificilmente podiam elaborar uma concepção moral baseada, no conjunto, na ética aristotélica. É o que precisa MacIntyre no começo do seu capítulo sobre a Idade Média, quando afirma que até mesmo Tomás de Aquino conheceu Aristóteles só em versões e traduções ${ }^{21}$. Seja o que for, o autor assinala que houve, no século XII, o que alguns chamam de "Renascimento medieval" (Paré, Brunet \& Tremblay, 1933; Gandillac \& Jeauneau, 1968; Benson, Constable \& Lanhan, 1982; MacIntyre, 1984, p. 167; Wetherbee, 1988, pp. 21-53), com a redescoberta de textos clássicos, como os de Macróbio, Virgílio, Cícero e outros, que permitiram o acesso ao pensamento moral dos antigos, notadamente de Aristóteles. É o caso de Abelardo, que não somente aproveitou essa chegada de novas obras literárias e filosóficas, mas também se beneficiou, como lógico notável, da logica uetus e dos comentários de Boécio sobre esse corpus de tratados.

18 "We possess indeed simulacra of morality, we continue to use many of the key expressions. But we have - very largely, if not entirely - lost our comprehension, both theoretical and practical, of morality. (...) the language and the appearances of morality persist even though the integral substance of morality has to a large degree been fragmented and then in part destroyed." (MacIntyre, 1984, pp. 2, 5).

${ }_{19}$ Traduzimos. "Alasdair MacIntyre agreed with Anscombe and carried her analysis further. In his view, modern societies have inherited no single ethical tradition from the past, but fragments of conflicting traditions: we are Platonic perfectionists in saluting gold medallists in the Olympics; utilitarians in applying the principle of triage to the wounded in war; Lockeans in affirming rights over property; Christians in idealizing charity, compassion and equal moral worth; and followers of Kant and Mill in affirming personal autonomy. No wonder that intuitions conflict in moral philosophy. No wonder people feel confused."

${ }^{20}$ Traduzimos. "Medieval Aspects and Occasions".

21 “(...) the medieval world encountered Aristotle relatively late and even Aquinas encountered him only in translation; and when it did encounter him, what he provided was at best a partial solution to a medieval problem which had already been stated time and again." (MacIntyre, 1984, p. 165). 
$\mathrm{Na}$ continuação, MacIntyre afirma que Abelardo tenta, na sua Ética, distinguir o vício do pecado ou da falta moral, como vimos, a partir da definição aristotélica da virtude ${ }^{22}$. De fato, na segunda parte do tratado em questão, encontra-se uma descrição inacabada da virtude transmitida por Boécio em termos aristotélicos. Não se deve esquecer, por um lado, que Abelardo reconstituiu o essencial da ontologia da virtude aristotélica a partir das Categorias, tratado que era acessível à sua época. Por outro lado, prossegue MacIntyre, Abelardo define, nesta vez no Dialogus, as virtudes cardeais e suas principais subespécies respectivas à maneira de Cícero, e não de Aristóteles (MacIntyre, 1984, p. 168). Além disso, acrescenta MacIntyre, Abelardo critica, por intermédio do Cristão, o Filósofo do Dialogus ${ }^{23}$ por apresentar uma concepção pagã do Bem supremo e por enfatizar a relação da vontade humana com o bem e o mal (MacIntyre, 1984, p. 168). Aonde quer chegar MacIntyre com essas observações? Continuamos ainda um pouco mais com o nosso exame da sua avaliação da ética abelardiana antes de responder a essa pergunta.

Em contraste com a ética aristotélica, a noção de vontade torna-se, segundo MacIntyre, a pedra angular da moral de Abelardo, que deixa em segundo plano a teoria da virtude e do seu contrário, o vício (MacIntyre, 1984, p. 168). Na sua análise da falta moral ou do pecado, o autor medieval deixa implicitamente entender que até o vicioso não age necessariamente de maneira errada, já que, como diz MacIntyre: "Tudo gira em torno do caráter do ato interior da vontade." (1984, p. 168) ${ }^{24}$. De fato, o maldoso tem tendência a agir mal, mas não comete falta nenhuma se não consente na atuação de sua natureza viciosa.

A análise de MacIntyre parece, até agora, exata, e corresponde à nossa explicação, na primeira parte deste trabalho, da identificação da falta moral ao consentimento na ética de Abelardo. A natureza virtuosa ou viciosa do agente moral torna-se simplesmente um elemento extrínseco à vontade, como o ato exterior. É preciso, todavia, corrigir o uso da palavra 'vontade' na explanação de MacIntyre, que emprega o termo no sentido agostiniano, como vimos anteriormente. Trata-se de um detalhe que tem sua importância, já que Abelardo evita uoluntas por causa da sua imprecisão.

Na continuação, MacIntyre mostra, de maneira convincente, que uma teoria ética que prioriza a interioridade da vontade sobre outros princípios externos origina-se não somente de alguns textos do Novo Testamento, mas, sobretudo, da filosofia dos estoicos antigos (MacIntyre, 1984, p. 168) ${ }^{25}$. Segundo a Escola do Pórtico, as boas ações dependem do agente que tem 'boa vontade', expressão equivalente a

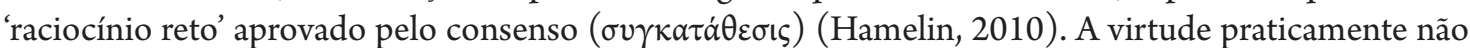

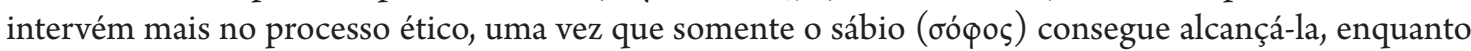
bem único. Na mesma ocasião, há um abandono da noção de finalidade ( $\tau \dot{\lambda} \lambda \circ \varsigma$ ), tal como exposta por Aristóteles, na medida em que essa vontade estoica deve conformar-se à Lei da natureza ou ao $\lambda o ́ \gamma o c$. Essa adequação à Lei universal opõe-se ao mundo das circunstâncias particulares e sociais. O resultado dessa transformação é que o fim do indivíduo está fora dele e viver bem significa, doravante, seguir a Ordem cósmica, e não mais seus próprios desejos e objetivos (MacIntyre, 1984, p. 168-170). Segundo os próprios termos de MacIntyre: "Em suma, se tenho razão, o estoicismo é uma resposta a um tipo particular de

22 "In Abelard's Ethics, written about 1138, the key distinction (...) is that beween a vice and a sin. What Abelard took to be Aristotle's definition of virtue, transmitted to him by Boethius, is put to use to provide a corresponding definition of a vice." (MacIntyre, 1984, p. 168). MacIntyre exagera aqui acerca do que é o essencial nesse tratado abelardiano. Mesmo que a questão seja a da distinção entre vício e pecado, Abelardo tenta, antes de tudo, mostrar nessa obra que o pecado consiste em consentir no mal, que é desprezar a Deus: "Vt ergo breui conclusione supradicta colligam (...) ipsum peccatum, quod in consensu mali uel contemptu dei statuimus (...).” (Abaelardus, 2001, p. 21).

${ }^{23} \mathrm{O}$ título completo da obra é: Dialogus inter Philosophum, Iudaeum et Christianum, também conhecido como Collationes. Portanto, o Cristão e o Filósofo em questão são, com o Judeu, as principais personagens desse tratado. Sobre os títulos dessa obra, ver (Abaelardus, 2001*, pp. xxiii-xxv).

${ }^{24}$ Traduzimos. "Everything turns on the character of the interior act of will."

${ }^{25}$ Charles H. Kahn defende uma tese semelhante. Ver (Kahn, 1988). 
desenvolvimento social e moral, um tipo de desenvolvimento que, impressionantemente, antecipa alguns aspectos da modernidade. (...) De fato, cada vez que as virtudes começam a perder seu lugar central, os padrões estoicos de pensamento e de ação imediatamente reaparecem." (1984, p. 170) ${ }^{26}$.

Vimos que a principal fonte da noção abelardiana de consensus é Agostinho. MacIntyre explica, na continuação do mesmo capítulo, a importância desse autor na concepção segundo a qual a natureza humana torna-se má por causa do consentimento dado pela vontade no mal. Esse mal é de tal essência que a vontade pode comprazer-se com ele. Por um lado, diz MacIntyre, Agostinho defende, como Abelardo, a ideia de que o mal é um desrespeito à lei divina; consentir no mal é justamente querer ofender essa lei (MacIntyre, 1984, p. 175). Por outro lado, as virtudes permitem combater esse mal, tal como é concebido por Agostinho e outros pensadores medievais, mas essas mesmas virtudes, adaptadas pelos cristãos ao seu modo de pensamento, não correspondem mais à teoria ética de Aristóteles (MacIntyre, 1984, p. 175176). Segundo este último, a virtude pode vencer a adversidade humana até certo ponto, mas os grandes infortúnios nos impedem de alcançar a felicidade. Na visão histórica cristã, ninguém é, ao contrário, excluído do bem; qualquer mal que pode acontecer a alguém não o impossibilita de se aproximar desse bem. No auge da Idade Média, a mesma diferença de concepção da virtude pode ser observada em Tomás de Aquino, como o afirma MacIntyre:

“(...) Aquino não pode, com certeza, querer dizer exatamente, com os nomes latinos das virtudes cardeais, o que Aristóteles queria dizer pelos seus equivalentes gregos, pois uma ou mais das virtudes cardeais deve conter nela ao mesmo tempo a paciência e outra virtude bíblica que Aquino explicitamente reconhece, a saber, a humildade. Todavia, no único lugar na explicação de Aristóteles das virtudes onde algo parecido com a humildade é mencionado, trata-se de um vício, e a paciência não é mencionada nem uma só vez por Aristóteles." (MacIntyre, 1984, p. 177) ${ }^{27}$.

A partir dessa breve análise, podemos inferir o essencial do que ressalta MacIntyre acerca da concepção moral abelardiana no que concerne à virtude. A primazia da ética de Abelardo diz respeito doravante às noções de escolha e de decisão, chamadas de consensus, que se referem ao ato interno mental correspondente, se for o caso, à falta moral, mas também à liberdade individual e à responsabilidade humana. As virtudes ficaram, de certa forma, em segundo plano ou, pelo menos, sua natureza foi parcialmente mudada. Houve uma inversão dos valores em relação à ética aristotélica, principalmente na tradição agostiniana, à qual pertence em boa parte Abelardo. Não se trata, todavia, de uma alteração da dimensão produzida pela filosofia moderna, já que as virtudes continuam a ter sua importância na concepção cristã, mas elas são transformadas a ponto de perderem uma parte da sua essência. Mesmo assim, o retorno à teoria original da virtude ainda fica indispensável e valioso, uma vez que somente essa qualidade permite tornar boa a vontade e, consequentemente, bom o consentimento e a ação externa correspondente.

\section{Conclusão: crítica da avaliação de MacIntyre da ética de Abelardo}

Antes de reagir diretamente à análise feita por MacIntyre da ética de Abelardo, queremos de início enfatizar a relevância e a pertinência da sua investigação geral acerca da teoria da virtude no decorrer da história da filosofia e da sua crítica da ética moderna. Concordamos, todavia, com a observação avançada por Long a respeito, desta vez, do exame de MacIntyre da ética aristotélica, segundo o qual falta, por vezes, a fina precisão necessária para bem entender o pensamento do Estagirita. Mas essa dificuldade não

${ }^{26}$ Traduzimos. "If I am right then, Stoicism is a response to one particular type of social and moral development, a type of development which strikingly anticipates some aspects of modernity. (...) Indeed whenever the virtues begin to lose their central place, Stoic patterns of thought and action at once reappear."

${ }^{27}$ Traduzimos. "(...) Aquinas cannot of course mean by the Latin names of the cardinal virtues entirely what Aristotle meant by their Greek equivalents, since one or more of the cardinal virtues must contain within itself both patience and another biblical virtue which Aquinas explicitly acknowledges, namely humility. Yet in the only place in Aristotle's account of the virtues where anything resembling humility is mentioned, it is as a vice, and patience is not mentioned at all by Aristotle." 
impede, acrescenta o comendador, apreciar a importância da tese geral que é defendida em After Virtue ${ }^{28}$. Uma crítica similar pode ser feita em relação ao estudo produzido por MacIntyre da ética de Abelardo, na medida em que são necessários alguns ajustes para compreender, de maneira adequada, a própria teoria da virtude abelardiana. Uma vez realizado esse exercício, é possível que seja inevitável, no final, adaptar algumas conclusões às quais chega MacIntyre.

Digamos de início que Abelardo não abandona a teoria aristotélica da virtude, apesar de enfatizar, na sua Ética, que o ato de consentimento constitua a falta moral. MacIntyre afirma, nesse contexto, que o lógico medieval define a noção de vício a partir do que considera ser a concepção da virtude de Aristóteles, tal como foi transmitida por Boécio ${ }^{29}$. Nesse caso, consideramos que o romano transmite, em diferentes Comentários sobre a lógica de Aristóteles, notadamente sobre as Categorias, a visão exata do Estagirita em relação à natureza da virtude como estado adquirido estável e quase permanente, ou seja, como habitus (Boethius, In Categorias Aristotelis iii, 1847, p. 242B-C; De divisione, 1847, p. 885B; De differentiis topicis ii, 1847, p. 1188C) ${ }^{30}$. Além disso, MacIntyre declara que Abelardo critica, através do Cristão do Dialogus, o Filósofo por ter definido a virtude em termos ciceronianos, e não aristotélicos, deixando de lado a importante relação entre a vontade humana e o bem ou o mal ${ }^{31}$. Em um contexto cristão, a noção de vontade torna-se, diz MacIntyre, prioritária, já que o caráter virtuoso ou vicioso de um indivíduo influencia, decerto, seu agir, mas não o determina; o que causa sua ação externa é a vontade, que consente ou não consente em agir segundo a lei divina ${ }^{32}$. O autor de After virtue conclui que: "Essa interiorização da vida moral, que enfatiza a vontade e a lei, refere-se não somente a alguns textos do Antigo Testamento, mas também ao estoicismo." (1984, p. 168) ${ }^{33}$.

Nos seus dois principais tratados éticos, Abelardo justamente focaliza o aspecto interior da falta moral não somente no Dialogus, mas também na Ética. Se MacIntyre quer deixar entender que a tendência de Abelardo é se afastar, ainda mais no seu Dialogus, da concepção aristotélica da virtude para se aproximar da visão volitiva dos estoicos em geral, e da de Agostinho em particular, então ele está confrontado com um problema quase insolúvel. Até hoje, os especialistas não podem afirmar com certeza a datação exata dessas duas obras, o que não permite seguir uma evolução possível do pensamento de Abelardo nessas

\footnotetext{
${ }^{28}$ Numa nota do seu livro Stoic Studies, Long afirma, no capítulo 7 intitulado Greek Ethics after MacIntyre: "In this paper I am not concerned with precise details of MacIntyre's interpretation of Aristotle himself. Some of what he says lacks the sharp analysis necessary to any clear determination of Aristotle's ethical position (...). But MacIntyre's characterization of an 'Aristotelian tradition', not specific to Aristotle, is broadly acceptable, and necessary to the kind of contrast between ancient and modern on which he is engaged." (1996, p. 159, nota 5).

29 "In Abelard's Ethics, (...), the key distinction which is put to the service of answering this question (How is the practice of the four cardinal virtues of justice, prudence, temperance and courage to be related to that of the theological virtues - faith, hope and charity?) is that between a vice and a sin. What Abelard took to be Aristotle's definition of virtue, transmitted to him by Boethius, is put to use to provide a corresponding definition of a vice." (MacIntyre, 1984, p. 168)

${ }^{30}$ Ver (Abaelardus, 2001, p. 86; 1971, p. 128, nota 3; Hamelin, 2015, pp. 75-94).

31 "Elsewhere (fora da Etica), in Abelard's Dialogue between a Philosopher, a Jew and a Christian, the Philosopher, who is the voice of the ancient world, lists and defines the cardinal virtues in Cicero's, not Aristotle's terms. Abelard's accusation against the philosopher is not only or even principally one of positive error; what he stresses are the errors of omission in the pagan moral view, the incompleteness of the pagan account of the virtues, even in its best representatives. This incompleteness is ascribed to the inadequacy both of the Philosopher's conception of the supreme good and of the Philosopher's beliefs about the relationship of the human will to good and evil." (MacIntyre, 1984, p. 168).

32 "What Christianity requires is a conception not merely of defects of character, or vices, but of breaches of divine law, of sins. An individual's character may at any given time be a compound of virtues and vices, and these dispositions will preempt the will to move in one direction or another. But it is always open to the will to assent to or dissent from these promptings." (MacIntyre, 1984, p. 168).

${ }^{33}$ Traduzimos. "This interiorization of the moral life with its stress on will and law looks back not only to certain New Testament texts, but also to Stoicism."
} 
questões morais ${ }^{34}$. O resultado é que não se pode manter que Abelardo distancia-se ainda mais no Dialogus da concepção aristotélica da virtude para privilegiar a tese estoico-cristã da volição. Como dissemos acima, quer no Dialogus, quer na Ética, Abelardo enfatiza as noções de vontade e de consentimento, sem abandonar ou deixar em segundo plano a teoria aristotélica da virtude.

É verdade que Abelardo tem tendência a interiorizar a vida moral nos seus dois tratados em estudo, como afirma MacIntyre, notadamente na Ética, em que o foco situa-se certamente mais na noção de consentimento do que na de vontade. Essa distinção é importante para Abelardo, que quer, como lógico, diferenciar nitidamente as duas realidades. Todavia, MacIntyre afirma, sem hesitação, que o ato de decisão interno para agir ou não agir, isto é, para pecar ou não pecar, é um ato da vontade ${ }^{35}$, o que não é unanimidade entre os especialistas ${ }^{36}$. Além disso, esse ato de vontade constitui, para o cristão, o único elemento essencial da vida moral, conclui MacIntyre: "A verdadeira cena da moralidade é a da vontade e da única vontade." $\left(1984\right.$, p. 168) ${ }^{37}$.

Enquanto a falta moral é aparentemente causada, para Agostinho, por um ato volitivo, Abelardo parece defender, antes, que se trate de um ato de razão, o que o aproximaria, mais uma vez, do pensamento aristotélico. Da mesma forma que o Estagirita distingue a vontade ( $\beta$ ov́ $\lambda \eta \sigma \varsigma)$, que vise racionalmente

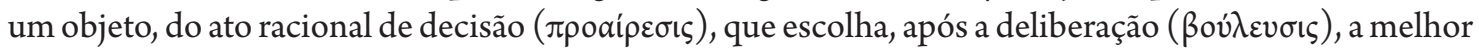
opção para alcançar esse mesmo objeto, Abelardo diferencia a vontade (uoluntas), que deseja algo, do consentimento (consensus), que decide, após a avaliação da prudência (prudentia) ${ }^{38}$, acatar ou não esse desejo. Nesse caso, a virtude aristotélica favorece não somente a escolha de um objeto bom, mas permite, sobretudo, a tomada de decisões perspicazes por meio da prudência ( $\varphi \rho o ́ v \eta \sigma \varsigma)$ para obter esse bem. Por isso, ao enfatizar a importância de adquirir as diversas virtudes morais estáveis e quase permanentes, assim como de conquistar a firme virtude intelectual da prudência, parece-nos claro que Abelardo segue de perto os passos de Aristóteles ${ }^{39}$. Deste modo, ele afasta-se irremediavelmente da concepção unitária da virtude estoica. Em suma, a vontade permite escolher um objeto, e a prudência deliberar com discernimento antes do consentimento. Não se deve esquecer, nesse tipo de análise, que Abelardo não defende, como será o caso no próximo século XIII com Tomás de Aquino, a existência de uma faculdade distinta de vontade.

Não é preciso aceitar a tese mais específica de Long, segundo a qual o sistema ético próprio da tradição aristotélica aproxima-se essencialmente do dos estoicos, para avaliar a interpretação geral feita por MacIntyre da moral abelardiana ${ }^{40}$. Pode ser exato que Abelardo defina, na Ética, o vício a partir da descrição da virtude, tal como transmitida por Boécio (Abaelardus, 1971, pp. 2-4, 32, 40, 128; 2001, pp.

\footnotetext{
${ }^{34}$ Para ter um esclarecimento relativamente completo da questão da datação desses dois tratados, ver (Abaelardus, $2001^{*}$, pp. xxvii-xxxii; Mews, 1985, pp. 104-126).

35 "But it is always open to the will to assent to or dissent from these promptings. (...) Everything turns on the character of the interior act of will. Character therefore, the arena of the virtues and vices, simply becomes one more circumstance, external to will." (MacIntyre, 1984, p. 168).

${ }^{36}$ A literatura sobre esse assunto é vasta e as opiniões são compartilhadas. Ver (Blomme, 1957, 1958, pp. 113-219; Siano, 1971; Gandillac, 1975, pp. 585-610; Marenbon, 1997, passim; Hamelin, 2010*, pp. 23-39).

${ }^{37}$ Traduzimos. "The true arena of morality is that of the will and of the will alone."

${ }^{38}$ Há um trecho na Ética, no qual não se encontra o termo prudentia, mas um sinônimo, provide (com previdência), ao qual é associada claramente a noção de razão: "Si ergo non tam pro honore sibi conseruando quam pro hac communi erubescencia ecclesiae confiteri distulit, prouide hoc, non superbe fecit. Timor quoque in causa racionabilis fuit de dampno ecclesie magis quam de proprie detrimento fame." (Abaelardus, 2001, p. 68).

${ }^{39}$ Além das virtudes morais, a virtude intelectual de prudência é particularmente importante para Abelardo nos seus dois principais tratados de ética. Ver (Abaelardus, 2001, p. 85; 2001*, pp. 130-134).

40 "MacIntyre appears to regard Stoicism as a different kind of moral system from the 'Aristotelian tradition' and this, I shall argue, is a mistake." (Long, 1996, p. 157).
} 
1-3, 21, 27, 85-86), mas o ponto de referência nesse caso é, sem dúvida, a teoria de Aristóteles e não a dos estoicos. Apesar de se referir aparentemente ao segundo livro inacabado da Ética ${ }^{41}$, MacIntyre parece esquecer que Abelardo trata ali da virtude em termos claramente aristotélicos. De fato, Abelardo tinha acesso, entre outras coisas, às Categorias, traduzidas e comentadas por Boécio, nas quais o autor define,

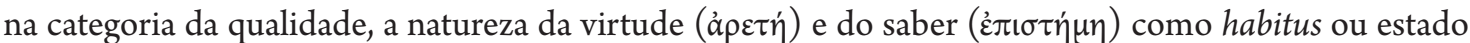
$(\varepsilon \xi \xi \varsigma \zeta)$ estável e quase permanente adquirido pela prática - no caso da virtude - e pelo estudo - no caso do saber ou conhecimento. A diversidade dessa qualidade adquirida transforma em profundidade o caráter $(\tilde{\eta} \theta 0 \varsigma)$ do indivíduo, que vai eventualmente consentir em agir bem graças à prudência, ou melhor, ao discernimento (prudentia).

No Dialogus, também se encontra uma descrição da natureza da virtude em termos parecidos aos da Ética. De novo, Abelardo faz referência, nessa ocasião, a Aristóteles e Boécio através do Filósofo do diálogo ${ }^{42}$. Na verdade, Abelardo alude a Cícero somente para descrever as quatro virtudes cardeais (Abaelardus, 2001*, pp. $130-138^{43}$ ) - as quais são atribuídas a Sócrates ${ }^{44}$-, pois conserva, como vimos, a importante ideia aristotélica acerca da essência da virtude. Além disso, Abelardo critica diretamente a concepção estoica da virtude por meio, desta vez, do Cristão ${ }^{45}$, notadamente a teoria dita da 'unidade da virtude', que reduz a uma só a diversidade das virtudes ${ }^{46}$. Esse único bem estoico é, afinal, conquistado somente pelo sábio estoico ( $\sigma o ́ \varphi \circ \varsigma)$, personagem enigmática e, sobretudo, inumana, que é a única a raciocinar de maneira infalível e a agir sempre conforme a Natureza e a Razão ( $\lambda$ ó $o \varsigma$ ) universal (Hamelin, 2010**).

\footnotetext{
41 "What Abelard took to be (na Ética) Aristotle's definition of virtue, transmitted to him by Boethius, is put to use to provide a corresponding definition of a vice." (MacIntyre, 1984, p. 168)

42 "Virtus, inquiunt, est habitus animi optimus; sic e contrario uitium arbitror esse habitum animi pessimum. Habitum uero hunc dicimus, quem Aristoteles in Categoriis distinxit, cum in habitu et dispositione primam qualitatis speciem comprehendit. Est igitur habitus qualitas rei non naturaliter insita, sed studio ac deliberatione conquisita et difficile mobilis. (...) Hic etiam, uirtutem omnem difficile mobilem esse asserens, cum in predicto Qualitatis tractatu Aristotilem exponeret scientias et virtutes inter habitus collocantem, "Virtus enim", inquit, "nisi difficile mutabilis non est. Neque enim qui semel iuste iudicat iustus est, neque qui semel adulterium facit est adulter, sed cum ista uoluntas cogitatioque permanserit." (...) Vnde Aristotiles, a uirtutibus scientias distinguens, cum in predicto Qualitatis tractatu de habitu exempla subiceret, “Tales”, inquit, "sunt scientie uel uirtutes." Quem quidem locum Boetius exponens ait: "Aristotiles enim uirtutes non putat scientias ut Socrates." (Abaelardus, 2001*, pp. 128-132)

${ }^{43} \mathrm{Na}$ sua apresentação das subespécies das virtudes cardeais, Abelardo também usa as descrições apresentadas por Cícero nos seus tratados De inuentione e De officiis, por Ambrósio também no seu De officiis e, enfim, por Macróbio no seu Sonho de Cipião.
} Ver (Abaelardus, $2001^{*}$, pp. 138 sqq, notadamente p. 139, nota 128).

44 "Socrates quidem, per quem primum uel maxime moralis discipline studium conualuit, quatuor uirtutis species distinguit: prudentiam scilicet, iustitiam, fortitudinem, temperantiam.” (Abaelardus, 2001*, p. 130).

${ }^{45}$ Nas últimas décadas, os especialistas de Abelardo examinaram em detalhes a seguinte questão: qual personagem do Dialogus defende o próprio pensamento de Abelardo. Na maioria dos casos, o Cristão parece apresentar as suas ideias, mesmo que o Filósofo também afirme ocasionalmente suas posições, notadamente na primeira parte do diálogo com o Judeu. Acerca desse assunto, Marenbon afirma: "In elaborating these doctrines (of Christianity) in a characteristically Abelardian way, as he does in the Christian's contributions, is Abelard not simply writing on his own behalf? The exact correspondence between the Christian's views and Abelard's own, on almost every occasion where a parallel allows the comparison to be made, seems to confirm this point." (Abaelardus, 2001*, p. liv) Ver (Jolivet, 1963, pp. 181-189; Marenbon, 1992, pp. 302 sqq.).

46 "Philosophus: Qui (Cicero) etiam in Paradoxis non solum in uirtutibus bonos, uerum etiam in peccatis ita equat malos, ut omnia peccata paria esse astruat. Christianus: Nunc primo te importunum impudenter fieri et corrixari magis quam philosophari uideo: quippe, ne ad confessionem manifete ueritatis cogi uidearis, ad patentissime falsitatis insaniam te conuertis, ut omnes uidelicet bonos equaliter bonos, omnes reos equaliter reos, et omnes pariter eadem gloria uel pena censeas dignos. Philosophus: (...) Quod si in caritate nemo alium transcendit, utique nec in uirtutibus aut meritis, cum omnem, ut dicis, caritas complectatur uirtutem. Christianus: (...) Et quamuis secundum specierum distinctionem omnes uirtutes aliquibus inesse concedamus, cum uidelicet unusquisque illorum sit iustus et fortis et temperans, non omnino tamen in uirtutibus aut meritis eos esse pares annuimus, cum alium alio iustiorem uel fortiorem seu modestiorem esse contigat." (Abaelardus, 2001*, pp. 116-120) Ver (Abaelardus, 1971, p. 74; 2001, p. 49). 
Em suma, ao enfatizar a intenção e a livre decisão ou o consentimento do agente moral na avaliação das suas ações, é verdade que Abelardo pode ser visto como um dos precursores da ética moderna. Nesse caso, a mesma observação também diz respeito a Agostinho, que sofreu a influência estoica sobre essa questão. É também exato que Abelardo defende, com rigor digno de um lógico, a teoria estoica da indiferença dos atos externos e retoma, via o filtro agostiniano, a ideia estoica de consentimento. No entanto, Abelardo nunca abandonou a complexa teoria aristotélica da virtude e sua importância na formação moral do indivíduo e na sua tomada de decisões práticas; o homem não é reduzido a uma pura vontade, sem desejo ou paixão, nem a uma simples razão. A virtude continua a ser primordial para alcançar a finalidade última. Enfim, seria talvez mais exato afirmar que Abelardo não é verdadeiramente um antecessor da ética moderna, mas, antes, o precursor da mais recente síntese, observada hoje em dia na ética contemporânea, da teoria da virtude com a dita teoria moderna dos valores (Silva Santos, 2001, pp. 327-357).

\section{Referências bibliográficas:}

Abaelardus (1855). Expositio in epistolam Pauli ad Romanos. Patrologia Latina. Vol. 178. J.-P. Migne (Ed). Paris: Vives.

(1969). Petri Abcelardi opera theologica. I. Commentaria in epistolam Pavli ad Romanos. Apologia contra Bernardvm. Corpvs Christianorvm. Continvatio Mediaeualis XI. E.M. Buytaert (Ed). Tvrnholti: Typographi Brepols Editores Pontificii.

(1971). Peter Abelard's Ethics. D.E. Luscombe (Ed). Oxford: Clarendon Press.

(2001). Petri Abaelardi Opera theologica. IV Scito te ipsvm. Rainer M. Ilgner (Ed.). Turnhout: Brepols Publishers.

$\left(2001^{*}\right)$. Peter Abelard. Collationes. Edited and translated by J. Marenbon and G. Orlandi. Oxford: Clarendon Press.

Anscombe, E. (1957). Intention. $1^{\text {st }}$ Ed. Oxford: Basil Blackwell.

(1958). "Modern Moral Philosophy”, Philosophy 33, pp. 1-19.

Aristoteles (1995). Aristotle. On the Soul. Parva Naturalia. On Breath. With an English translation by W.S. Hett. Cambridge, Massachusetts/London, England: Havard University Press.

Augustinus (1841). Expositio ad Romanos XIII-XVIII. Patrologia Latina. Vol. 35. J.-P. Migne (Ed). Paris: Vives.

(1845). De continentia liber unus. Patrologia Latina. Vol. 40. J.-P. Migne (Ed). Paris: Vives.

Baron, M. (1985). "Varieties of Ethics of Virtue", American Philosophical Quarterly, vol. 22, nº 1, January.

Benson, Constable \& Lanhan (Eds) (1982). Renaissance and Renewal in the Twelfth Century. Oxford: Clarendon Press.

Blomme, R. (1957). "À propos de la définition du péché chez Pierre Abélard", Ephemerides theologicae Lovanienses XXXIII, pp. 319-347.

(1958). La doctrine du péché dans les écoles théologiques de la première moitié du XIIe siècle. Louvain/Gembloux: Publications universitaires de Louvain/Éditions J. Duculot, S. A. 
Boethius (1847). In Categorias Aristotelis iii. “Patrologia Latina. Vol. 64. J.-P. Migne (Ed). Paris: J. P. Migne Editorem.

Cross, F. L. and Levingstone, E.A. (Eds) (1974). "Penance" e "Penitential Books", The Oxford Dictionary of the Christian Church. Second Edition. Oxford: Oxford University Press, pp. 1059-1060.

Foot, P. (1967). Theories of Ethics. Oxford: Oxford University Press.

(1978). Virtues and Vices and Other Essays in Moral Philosophy. Berkeley: University of California

Press.

Gandillac, M. de (1975). "Intention et loi dans l'éthique d'Abélard”, Pierre Abélard et Pierre Le Vénérable. Paris: Éditions du Centre national de la recherche scientifique, pp. 585-610.

Gandillac \& Jeauneau (Eds) (1968). Entretiens sur la Renaissance du 12e siècle. Paris: Mouton \& Co.

Garmus, L. (Ed) (1986). Bíblia Sagrada. Petrópolis: Vozes.

Hamelin, G. (1996). L'origine de la doctrine de la vertu comme habitus chez Pierre Abélard. Trois-Rivières (Canada): Université du Québec à Trois-Rivières.

(2010). "As fontes aristotélicas e estoicas em Abelardo: a noção de consentimento (consensus)

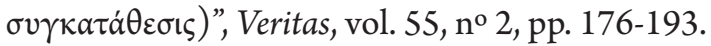

(2010*). "Vontade (boulesis) e consentimento (sunkatathesis) em Aristóteles e Abelardo: atos do apetite (orexis) ou da razão (logos)?”, Dois pontos. Curitiba/São Carlos, vol. 7, no 1, pp. 23-39.

$\left(2010^{* *}\right)$. "Il saggio (sophós) stoico possiede il discernimento (phrónesis) aristotelico?" Pensare la città antica: categorie e rappresentazioni. Philosophica I. Casertano, G \& G. Cornelli (Org). Napoli: Loffredo Editore University Press, pp. 107-120.

131, jun., pp. 75-94.

(2015). "Habitus e virtude em Pedro Abelardo: uma dupla herança", Kriterion, vol. 56, n.

Horton, J. \& Mendus, S. (Eds) (1994). After MacIntyre. Critical Perspectives on the Work of Alasdair MacIntyre. Notre Dame: University of Notre Dame Press.

Jolivet, J. (1963). "Abélard et le philosophe (Occident et Islam au XIIe siècle)", Revue d'histoire des religions 164, pp. 181-189.

Éditions Du Cerf.

(1994). Abélard ou la philosophie dans le langage. Fribourg/Paris: Éditions universitaires/

Kahn, C. H. (1988). "Discovering Will. From Aristotle to Augustine”, The Question of "Eclecticism". Studies in Later Greek Philosophy. Edited by J.M. Dillon and A. A. Long. Berkeley: University of California Press, pp. 234-259.

Long, A. A. (1996). Stoic Studies. Berkeley: University of California Press.

Long, A. A. \& Sedley, D.N. (Eds) (1987). The Hellenistic Philosophers. Vol. II. Greek and Latin Texts, with Notes and Bibliography. Cambridge: Cambridge University Press. 
Lottin, O. (1942). Psychologie et morale aux XIIe et XIIIe siècles. Tome I. Problèmes de Psychologie. Louvain - Gembloux: Abbaye du Mont César - J. Duculot.

MacIntyre, A. (1984). After Virtue. A Study in Moral Theory. $2^{\text {nd }}$ Ed. Notre Dame: University of Notre Dame Press.

Marenbon, J. (1992). "Abelard's Ethical Theory: Two Definitions From The Collationes", From Athens to Chartres. Neoplatonism and Medieval Thought. Studies in honour of Edouard Jeauneau. H.J. Westra (Ed). Studien und Texte zur Geistesgeschichte des Mittelalters XXXV. Leiden: E.J. Brill, pp. 301-314.

(1997). The Philosophy of Peter Abelard. Cambridge: Cambridge University Press.

Mews, C. (1985). "On Dating the Works of Peter Abelard", Archives d'histoire doctrinale et littéraire du moyen âge, v. 52, pp. 73-134.

O’Daly, G. (1987). Augustine's Philosophy of Mind. Berkeley \& Los Angeles: University of California Press.

Paré, Brunet \& Tremblay (1933). La renaissance du XIIe siècle. Les écoles et l'enseignement. Paris/Ottawa: Librairie philosophique J. Vrin/Inst. d'études médiévales.

Pence, G. (1991). "Virtue Theory", A Companion to Ethics. P. Singer (Ed). Oxford: Basil Blackwell, pp. 249-258.

Rohmer,J. (1954). “L'intentionnalité des sensations chez saint Augustin”, Augustinus Magister 1, pp. 491-498.

Siano, F. de. (1971). "Of God and Man: Consequences of Abelard's Ethic", The Thomist, vol. xxxv, no 4, pp. 631-660.

Silva Santos, Bento (2001). "Virtude e dever nas teorias éticas modernas. Naufrágio e sobrevivência de uma novidade antiga”, Síntese Nova fase. Revista de filosofia, vol. 28, no 92, pp. 327-357.

Voelke, A.-J. (1973). L'idée de volonté dans le stoïcisme. Paris: Presses universitaires de France.

Wetherbee, W. (1988). "Philosophy, Cosmology, and the Twelfth-Century Renaissance", A History of Twelfth-Century Western Philosophy. P. Dronke (Ed). Cambridge: Cambridge University Press, pp. 21-53.

Recebido em 01 de julho de 2020. Aceito em 25 de janeiro de 2021. 